\title{
Common accessory ossicles of the foot: imaging features, pitfalls and associated pathology
}

Bimal Mayur Kumar $\underline{\text { Vora }}^{1}$, MBBS, FRCR, Bak Siew Steven $\underline{\text { Wong }}^{2}$, MBChB, MMed

\begin{abstract}
Accessory ossicles are normal variants that are frequently seen but often overlooked or misdiagnosed. Commonly seen at the foot and ankle, they may be mistaken for fracture fragments or loose bodies, or not be recognised as a cause of the patient's symptoms. This pictorial essay aimed to review commonly encountered accessory ossicles of the foot and ankle by highlighting anatomic landmarks and associated pathologic processes through the use of both basic and advanced imaging modalities, in an effort to increase awareness of these clinical entities.
\end{abstract}

Keywords: accessory ossicles, foot, radiology, sesamoids

\section{INTRODUCTION}

Accessory ossicles are well-corticated bony structures found close to bones or a joint. They result from unfused ossification centres and are frequently congenital. They may, however, also be the result of prior trauma. Accessory ossicles can be found adjacent to various joints, such as the wrist, shoulder, hip or knee, but the foot and ankle are relatively common locations.

Accessory ossicles are usually an incidental finding on radiographs and often overlooked. At times, they mimic fractures or loose bodies, proving to be a diagnostic conundrum, thus leading to misdiagnoses. They may also contribute to or exacerbate underlying pathology, giving rise to symptoms. Higher modalities, such as computed tomography $(\mathrm{CT})$, magnetic resonance $(\mathrm{MR})$ imaging and even scintigraphy, are used in cases with diagnostic difficulty or when resulting pathology is suspected. This paper aimed to provide a pictorial representation of the more commonly encountered accessory ossicles of the foot and ankle, and showcase their anatomic features, resulting pathology and potential pitfalls in diagnosis.

\section{ACCESSORY NAVICULAR}

Three types of accessory navicular have been described. Type 1 accessory navicular (Fig. 1) is found within the posterior tibial tendon, close to its attachment to the navicular, and makes up about $30 \%$ of cases. It is typically small, measuring about $2-3 \mathrm{~mm}$ in size, does not have a cartilaginous interface with the navicular and is considered to be a sesamoid bone of the posterior tibial tendon. ${ }^{(1)}$ Type 2 accessory navicular (Fig. 2), seen in about $50 \%$ of cases, is located close to the median eminence of the navicular bone, forming a flat facet with an intervening synchondrosis, which is a cartilaginous interface between the accessory navicular and the navicular bone. Type 3 accessory navicular (Fig. 3), which makes up the remaining $20 \%$ of cases, is a fused ossification

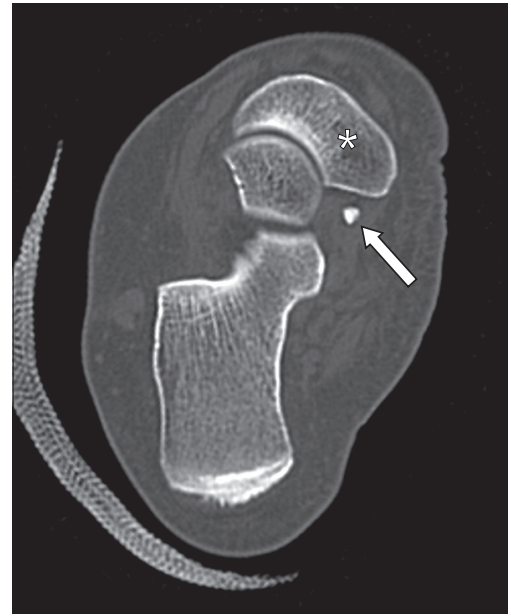

Fig. 1 Type 1 accessory navicular. Axial CT image of the foot shows an ossicle (arrow) measuring about $3 \mathrm{~mm}$ in size, adjacent to the navicular (asterisk) and within the tibialis posterior tendon.

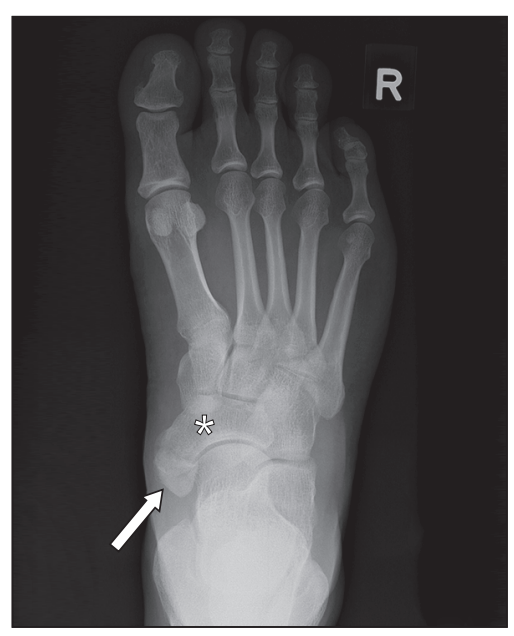

Fig. 2 Type 2 accessory navicular. Right foot radiograph shows an accessory navicular (arrow) forming a flat facet with an intervening synchondrosis at the median eminence of the navicular (asterisk). 


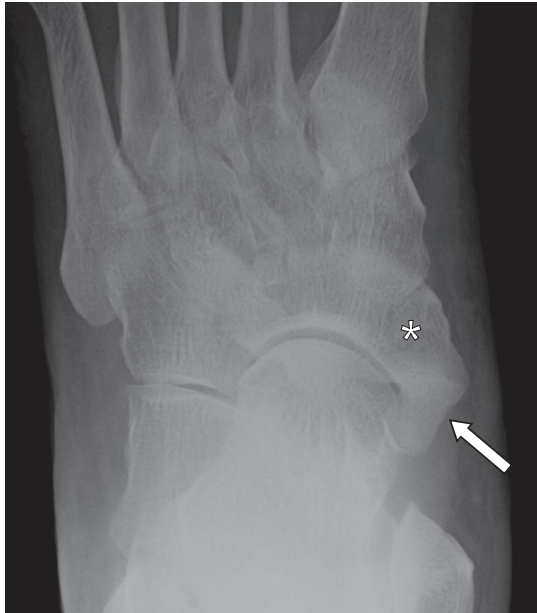

Fig. 3 Type 3 accessory navicular. Left foot radiograph shows an accessory navicular that has fused with the navicular bone (asterisk), resulting in a prominent median eminence (arrow).
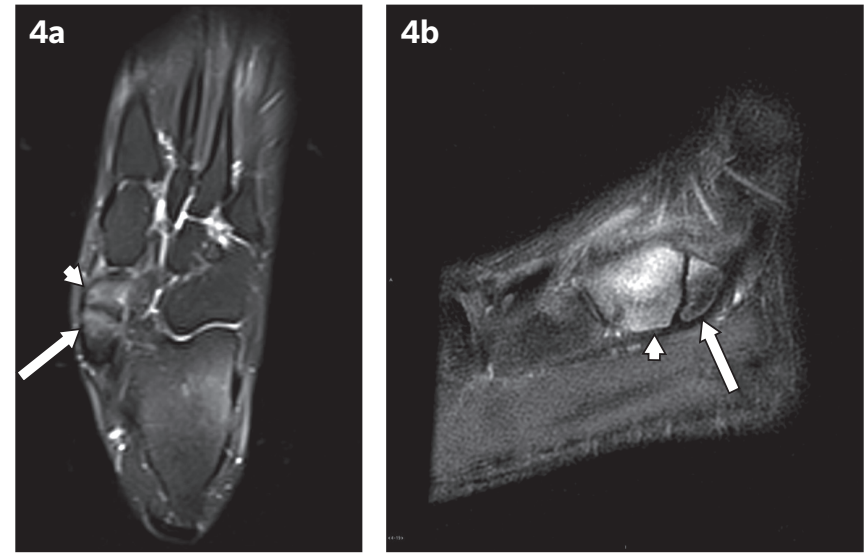

Fig. 4 Os naviculare syndrome. (a) Axial and (b) sagittal T2-W MR images from two different patients with medial foot pain and tenderness show bony oedema in Type 2 accessory naviculars (arrows in a \& b) and the navicular bones (arrowheads in a \& b) across the synchondrosis, as shown by increased T2-W signal within the bones.
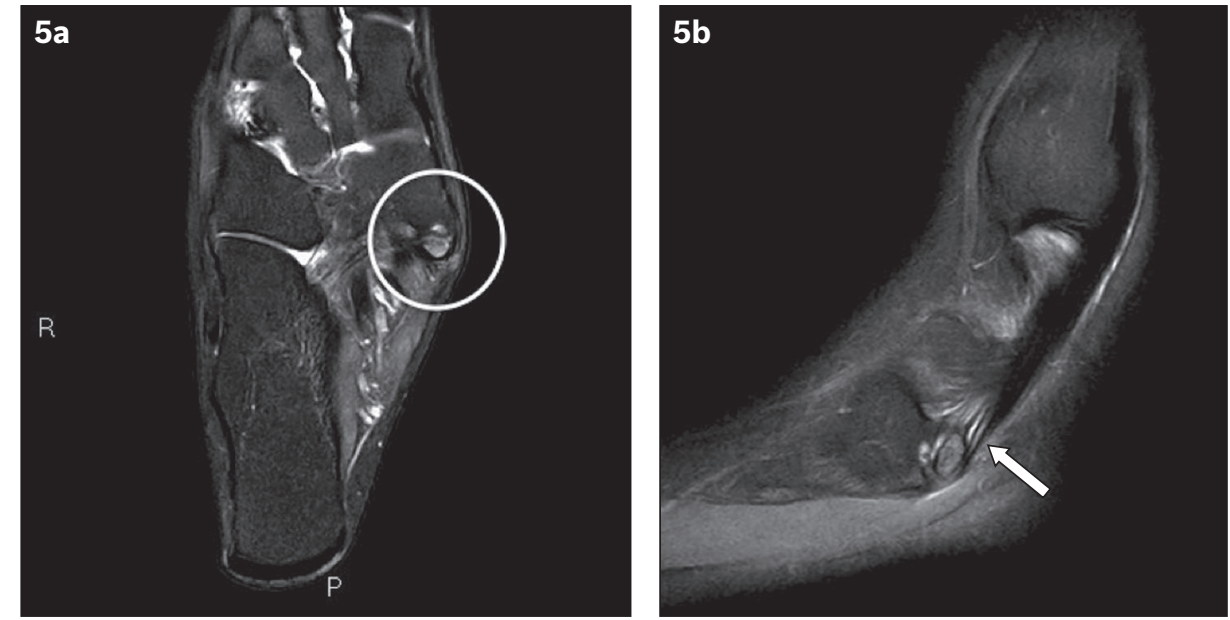

Fig. 5 Painful accessory navicular. (a) Axial T2-W MR image shows bony oedema in both the accessory ossicle and adjacent navicular bone (circle). (b) Sagittal MR image shows oedema (arrow) in the tibialis posterior tendon, in keeping with accessory navicular syndrome.

centre, resulting in a prominent median eminence, ${ }^{(1)}$ and there is no synchondrosis. The accessory navicular is bilateral in about $50 \%$ of cases $^{(2)}$ and is more common in women. Its overall prevalence is about $2 \%-21 \%$, making it the second most common accessory ossicle. ${ }^{(2)}$

Of the three types of accessory navicular, Type 2 is most commonly symptomatic, presenting as medial foot pain. ${ }^{(3)}$ This is also known as os naviculare syndrome. Shear stress at the synchondrosis caused by pull of the posterior tibial tendon is thought to be a cause. ${ }^{(4)} \mathrm{MR}$ imaging is usually required to establish the diagnosis in symptomatic cases. Bone marrow oedema of the accessory navicular and the articulating navicular (Fig. 4), and thickening of the posterior tibial tendon (Fig. 5) are some features that may be observed in os naviculare syndrome. ${ }^{(5)}$ Posterior tibial tendon tears may also be seen. ${ }^{(5)}$

\section{OS TRIGONUM}

The os trigonum is situated posteriorly to the talus and may be triangular or ovoid in shape (Fig. 6). A synchondrosis exists between the ossicle and the talus. The os trigonum has a reported prevalence of $7 \%-25 \%{ }^{(2)}$ and is best seen on the lateral projection.

The os trigonum may contribute to posterior ankle impingement syndrome (Figs. 7 \& 8), which is associated with repeated plantar flexion, ${ }^{(6)}$ and presents as posterior ankle pain and swelling. Imaging findings include soft tissue swelling, synovitis and flexor hallucis longus (FHL) tendon tenosynovitis. The FHL tendon traverses medially to the os trigonum, and repetitive stress or compression to the tendon with plantar flexion can result in inflammation (Fig. 8). ${ }^{(7)}$ Chronic impingement can result in degenerative change at the synchondrosis, with cystic and sclerotic changes on both sides of the synchondrosis.

A differential diagnosis for a bony opacity that is posterior to the talus is a fracture of the fused trigonal process of the talus, which may result from forceful plantar flexion. It also results in posterior ankle pain, but in this case, knowing the acute history of the pain would be helpful in diagnosis. ${ }^{(6)}$ Another common differential is a fracture of the lateral process of the talus (i.e. Shepherd's fracture). ${ }^{(2,6)}$ 

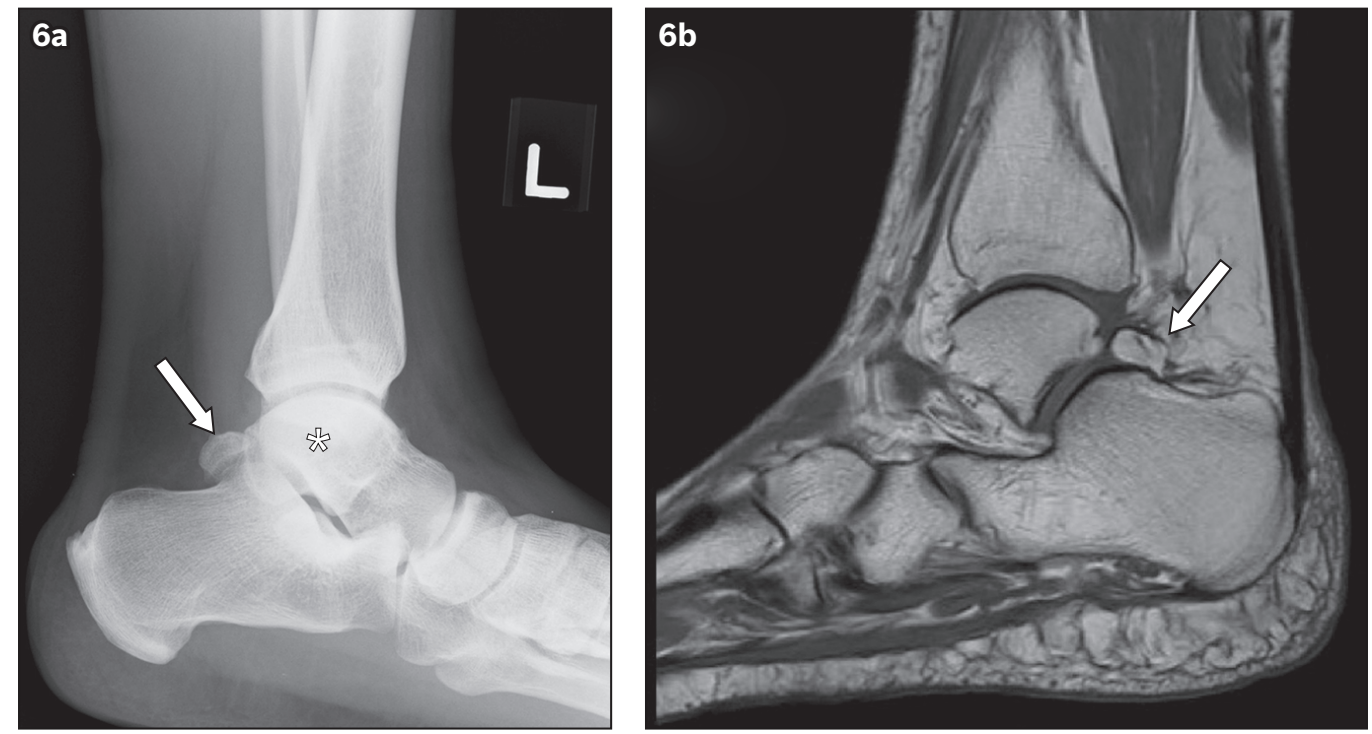

Fig. 6 Os trigonum. (a) Lateral radiograph of the ankle shows an ovoid bony structure (arrow) posterior to the talus (asterisk). The structure is well corticated, likely representing an os trigonum rather than a fracture. (b) Sagittal T1-weighted MR image shows an os trigonum (arrow) with a synchondrosis between the ossicle and talus.
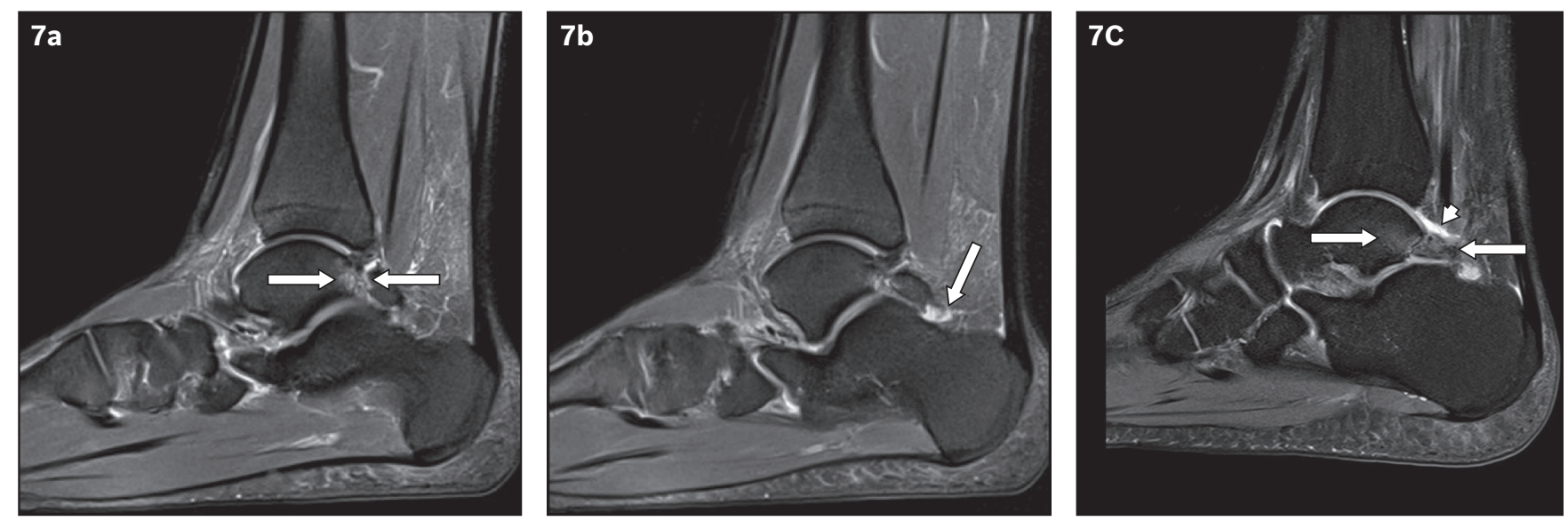

Fig. 7 Posterior ankle impingement syndrome. (a \& b) Sagittal T2-W MR images show bony oedema (arrows in a) in the ossicle and posterior talus at the synchondrosis. There is also synovitis with a small effusion (arrow in b) at the posterior ankle. (c) Sagittal MR image of the ankle of a 26-year-old man who presented with posterior ankle pain also shows bony oedema (arrows) in the posterior talus and os trigonum, with a small joint effusion (arrowhead)
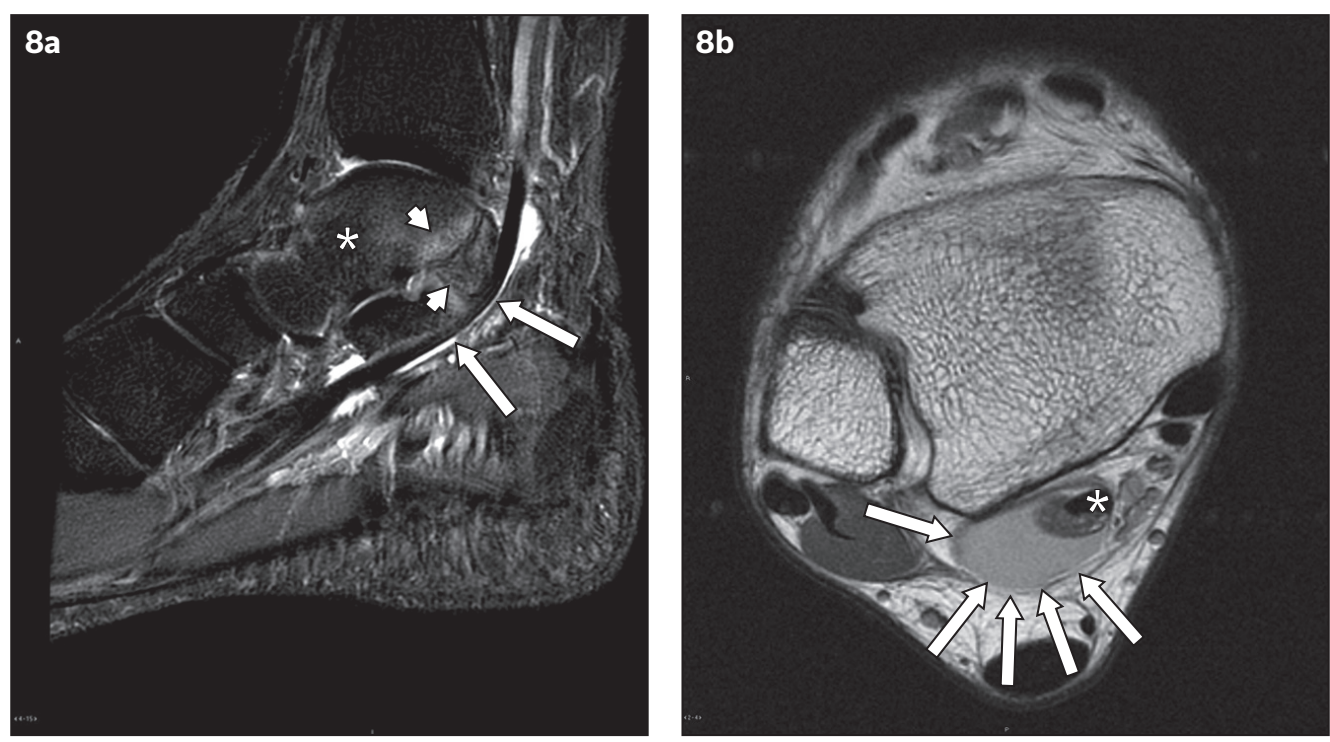

Fig. 8 Posterior ankle impingement syndrome. (a) Sagittal T2-W MR image shows bony oedema (arrowheads) in the talus (asterisk) and os trigonum posteriorly, with fluid surrounding the flexor hallucis longus tendon (arrows), which suggests tenosynovitis. (b) Axial proton-density MR image of the same patient with posterior impingement better demonstrates the fluid (arrows) surrounding the flexor hallucis longus tendon (asterisk), which suggests tenosynovitis. 

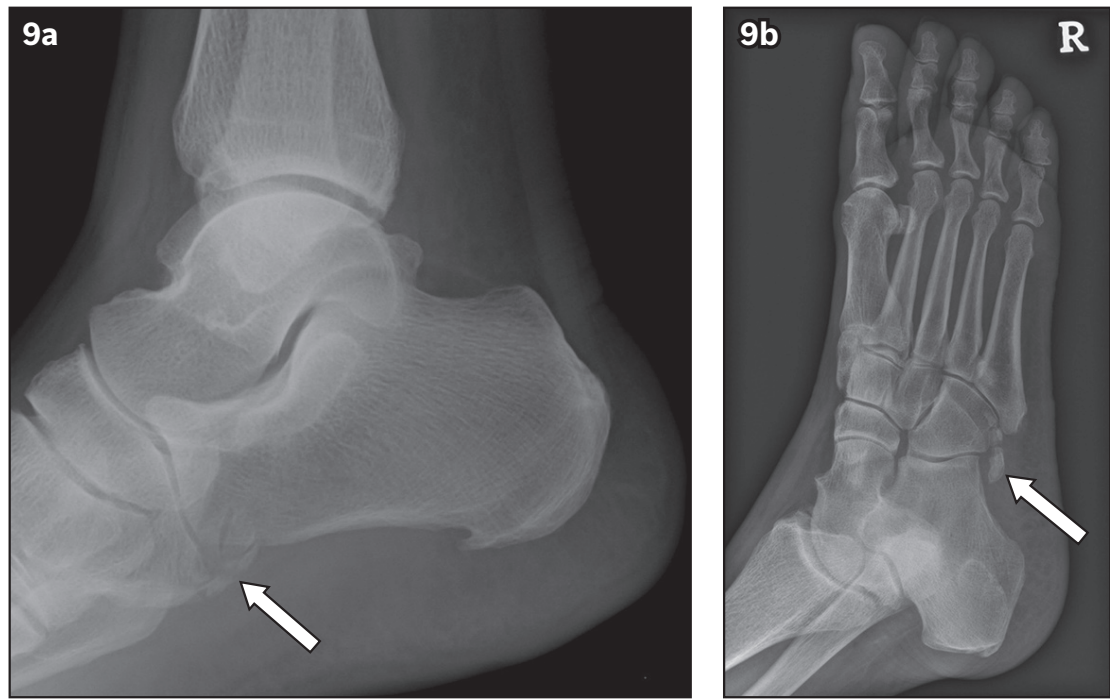

Fig. 9 Os peroneum. (a) Lateral ankle radiograph shows a few bony opacities (arrow) projected over the calcaneocuboid joint in an 81-year-old patient who presented with ankle pain. This represents the os peroneum which, in this case, appears fragmented. (b) This is similarly witnessed on the oblique view (arrow), raising the possibility of a fracture of the ossicle. MR imaging was subsequently performed.
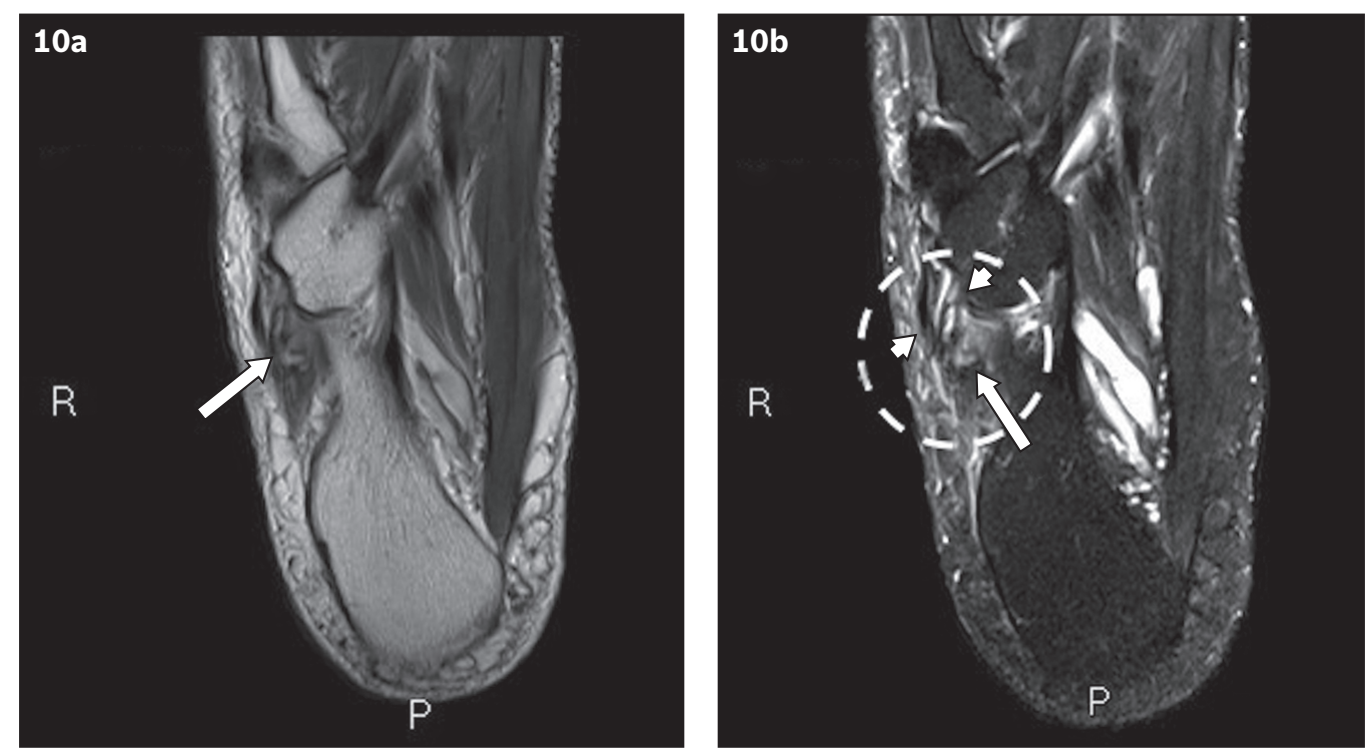

Fig. 10 (a) Axial T1-W MR image of the patient from Fig. 9 shows a fragmented os peroneum (arrow) in the thickened peroneus longus tendon. (b) T2-W MR image shows bony oedema in the os peroneum (arrow). The peroneus longus tendon is oedematous in the region of the ossicle (circle), with suggestion of a split tear (arrowheads). This is suggestive of a fracture of the os peroneum and probably explains the patient's pain.

\section{OS PERONEUM}

The os peroneum is located adjacent to the calcaneocuboid joint (Fig. 9) and embedded within the peroneus longus tendon. It is best seen on lateral or oblique views of the foot. The os peroneum may be bipartite in $30 \%$ of cases and bilateral in $60 \%$ of cases. ${ }^{(8)}$

The os peroneum may become symptomatic, presenting as lateral foot pain ${ }^{(9)}$ and tenderness, which is also known as painful os peroneum syndrome. This can be due to fracture of the ossicle (Fig. 10) or degeneration. ${ }^{(8)}$ It can result in a tear of the peroneus longus tendon that is evidenced by a displaced os peroneum on imaging. ${ }^{(10)}$ MR imaging (Fig. 10) may show abnormal T2 signal within the ossicle and tendinosis of the peroneus longus tendon. ${ }^{(2)}$ Ultrasonography may also be used to demonstrate inflammatory change in the soft tissue, and tendon tears or tenosynovitis of the peroneus longus tendon. ${ }^{(10)}$

\section{OS VESALIANUM}

The os vesalianum (Fig. 11) is situated proximal to the base of the fifth metatarsal, within the peroneus brevis tendon. ${ }^{(2)}$ It may be seen in about $0.1 \%-1.0 \%$ of individuals ${ }^{(11)}$ and must be differentiated from an apophysis of the fifth metatarsal, which is oriented parallel to the metatarsal shaft. The os vesalianum rarely causes symptoms. In the setting of pain, other diagnoses should also be considered, such as a fracture of the fifth metatarsal base or apophysitis, which is inflammation of the apophysis at the fifth metatarsal base. 


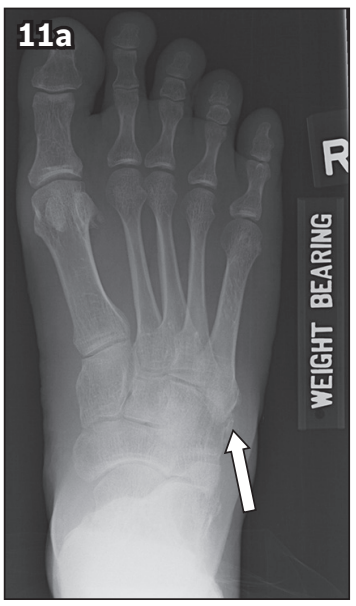

Fig. 11 Os vesalianum. (a) Right foot radiograph shows an os vesalinum (arrow) proximal to the fifth metatarsal base. The differential for a bony opacity in this region is an unfused apophysis orientated parallel to the cortex of the metatarsal base. (b) Lateral projection of the right foot radiograph of the same patient shows two accessory ossicles, an os peroneum proximally (arrow) and a smaller os vesalianum (arrowhead) distally.
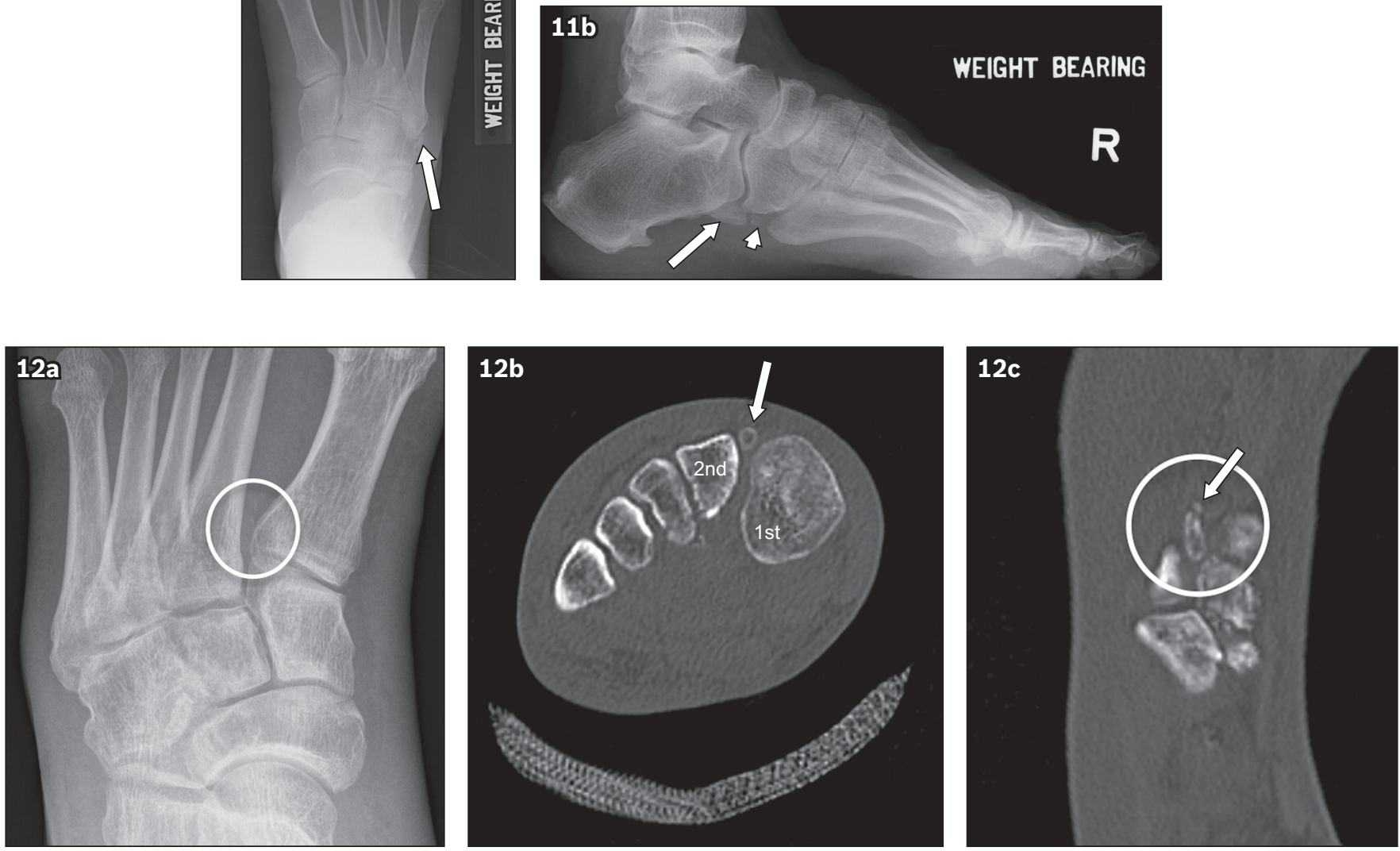

Fig. 12 Os intermetatarseum. (a) Foot radiograph and (b) coronal CT image show a bony opacity (circle in a \& arrow in b) between the bases of the first and second metatarsals. (c) CT image shows that the bony opacity is well corticated, apart from a fracture at its distal aspect (arrow). This is in keeping with a fractured os intermetatarseum.

\section{OS INTERMETATARSEUM}

The os intermetatarseum (Fig. 12) is situated between the first and second metatarsals. Three types have been described; it may be (a) free-standing, having no articulation with the adjacent bones; (b) articulating, forming a joint between the first or second metatarsal bases and/or the medial cuneiform, in any combination; (c) fused, arising as a spur from any of the adjacent bones. The reported incidence shows variation between anatomical studies (up to $13 \%$ ) and radiological studies (up to $7 \%) .{ }^{(2)}$ This variation may be due to the difficulty in identifying these small ossicles that can be easily obscured on radiographs by adjacent bony structures.

This ossicle may occasionally be symptomatic, presenting as dorsal foot pain or paraesthesia with numbness over the first intermetatarsal space, probably due to compression of the branches of the deep peroneal nerve. ${ }^{(12,13)}$ The onset usually follows trauma, with other reported inciting factors such as tight footwear and cavus feet. ${ }^{(12)}$ The os intermetatarseum may also be mistaken for a fracture at the base of the second metatarsal, which occurs in Lisfranc injuries. We present a case of a fractured os intermetatarseum in a patient post-trauma (Fig. 12).
Symptomatic os intermetatarseum is usually treated conservatively with nonsteroidal anti-inflammatory drugs and footwear or activity modification, failing which, surgical excision may be considered. ${ }^{(12)}$

\section{SESAMOIDS}

Sesamoids of the foot can be subdivided into hallucal, interphalangeal joint and lesser metatarsal sesamoids. ${ }^{(2)}$ In humans, hallucal sesamoids are invariably present. Hallucal sesamoids have medial and lateral components (Fig. 13). They can be bipartite, which is usually seen in the medial sesamoid if this occurs.

A common pitfall is mistaking a bipartite sesamoid for a fractured sesamoid. Other pathologies involving sesamoids include degenerative change, infection and osteonecrosis. ${ }^{(2)}$ Chronic pain over the sesamoids, often referred to as sesamoiditis, can occur from chronic stress and repetitive injury to the sesamoid. It most commonly involves the hallucal sesamoid. MR imaging (Fig. 14) is useful for diagnosis and shows abnormal signals in the sesamoids and surrounding soft tissue inflammation (i.e. tendinitis or synovitis). ${ }^{(2,14,15)}$ Bone scintigraphy may also be helpful in difficult cases to show increased tracer uptake in the sesamoids. ${ }^{(2,15)}$ 

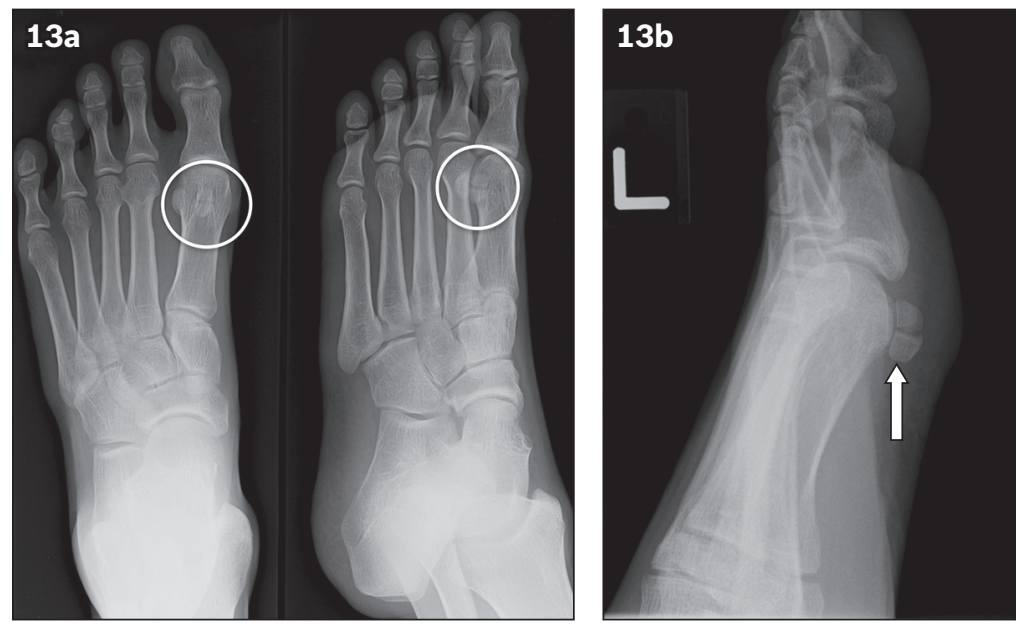

Fig. 13 ( $a$ \& b) Radiographs show that the medial sesamoid of the first metatarsal is made out of two parts (circles in a \& arrow in b). Both parts are well corticated. Hence, this is probably a bipartite sesamoid rather than an acute fracture. Old fractures that have healed can, however, have a similar appearance.
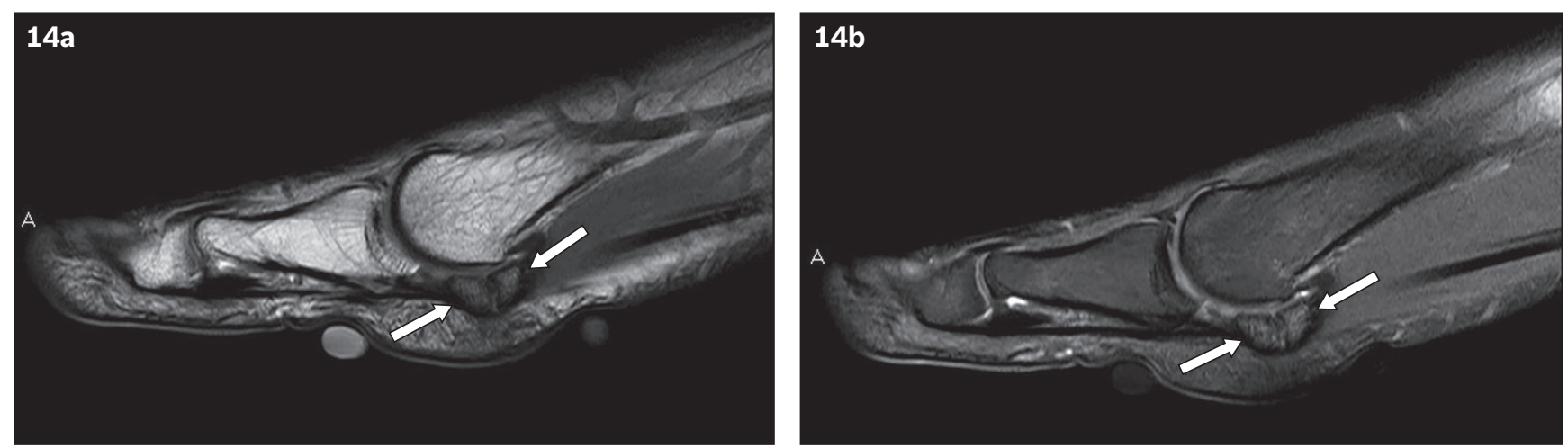

Fig. 14 A patient experienced chronic pain over the metatarsal head and was suspected to have sesamoiditis. (a) Sagittal T1-W MR image shows low T1-W signal in the medial sesamoid (arrows). (b) Sagittal T2-W MR image shows increased signal in the medial sesamoid (arrows) indicating bony oedema, which is suspicious for sesamoiditis.

\section{CONCLUSION}

There are many different accessory ossicles of the foot, only some of which have been featured in this article. It is important to recognise the existence of these ossicles, as they can be an important cause of a patient's symptoms. Being cognisant of these ossicles also prevents us from misdiagnosing them as fractures in the setting of foot pain, which is a commonly encountered situation. Apart from radiographs, advanced imaging techniques such as $\mathrm{CT}$, MR imaging and even ultrasonography or nuclear medicine techniques can be helpful in establishing the diagnosis in difficult cases and evaluating foot pain secondary to accessory ossicles.

\section{REFERENCES}

1. Lawson JP, Ogden JA, Sella E, Barwick KW. The painful accessory navicular. Skeletal Radiol 1984; 12:250-62.

2. Nwawka OK, Hayashi D, Diaz LE, et al. Sesamoids and accessory ossicles of the foot: anatomical variability and related pathology. Insights Imaging 2013; 4:581-93.

3. Miller TT. Painful accessory bones of the foot. Semin Musculoskelet Radiol 2002; 6:153-61.

4. Sella EJ, Lawson JP, Ogden JA. The accessory navicular synchondrosis. Clin Orthop Relat Res 1986; (209):280-5.
5. Choi YS, Lee KT, Kang HS, Kim EK. MR imaging findings of painful type II accessory navicular bone: correlation with surgical and pathologic studies. Korean J Radiol 2004; 5:274-9.

6. Lee JC, Calder JD, Healy JC. Posterior impingement syndromes of the ankle. Semin Musculoskelet Radiol 2008; 12:154-69.

7. Lo LD, Schweitzer ME, Fan JK, Wapner KL, Hecht PJ. MR imaging findings of entrapment of the flexor hallucis longus tendon. AJR Am J Roentgenol 2001; 176:1145-8.

8. Sobel M, Pavlov H, Geppert MJ, et al. Painful os peroneum syndrome: a spectrum of conditions responsible for plantar lateral foot pain. Foot Ankle Int 1994; 15:112-24.

9. Gökkuş K, Sagtas E, Demirci E, Saylik M, Aydın AT. Degenerative arthritis of pseudoarticulation between the os peroneum and cuboid: a rare cause of lateral foot pain. Foot Ankle Surg 2015; 21:e9-e11.

10. Brigido MK, Fessell DP, Jacobson JA, et al. Radiography and US of os peroneum fractures and associated peroneal tendon injuries: initial experience. Radiology 2005; 237:235-41.

11. Boya H, Ozcan O, Tandoğan R, Günal I, Araç S. Os vesalianum pedis. J Am Podiatr Med Assoc 2005; 95:583-5.

12. Nakasa T, Fukuhara K, Adachi N, Ochi M. Painful os intermetatarseum in athletes: report of four cases and review of the literature. Arch Orthop Trauma Surg 2007; 127:261-4.

13. Summers A. Accessory ossicles and sesamoid bones: recognition and treatment. Emerg Nurse 2015; 22:27-32.

14. Ashman CJ, Klecker RJ, Yu JS. Forefoot pain involving the metatarsal region: differential diagnosis with MR imaging. Radiographics 2001; 21:1425-40.

15. Mellado JM, Ramos A, Salvadó E, et al. Accessory ossicles and sesamoid bones of the ankle and foot: imaging findings, clinical significance and differential diagnosis. Eur Radiol 2003; 13 Suppl 6:L164-77. 


\section{SINGAPORE MEDICAL COUNCIL CATEGORY 3B CME PROGRAMME} (Code SMJ 201804B)

Question 1. Regarding accessory ossicles:

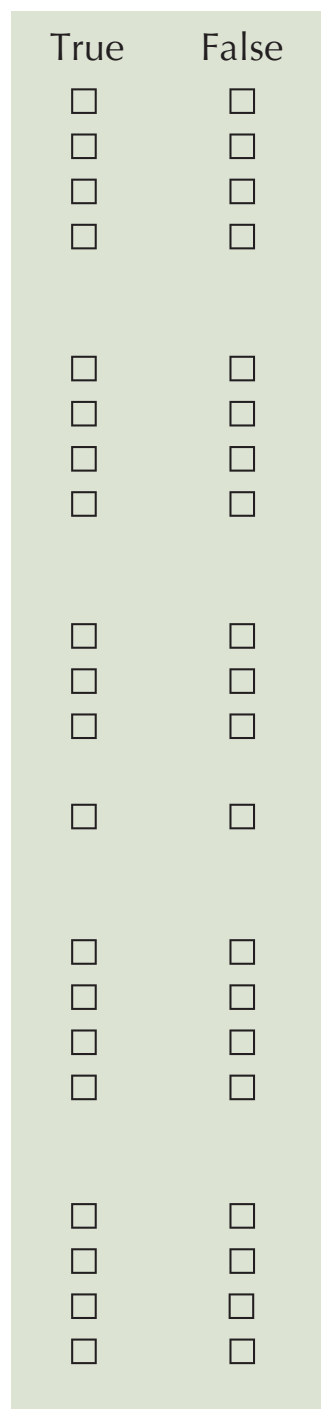

a) They are only found in the foot.

b) They are usually congenital.

c) They are usually symptomatic.

d) They may mimic fractures.

Question 2. Regarding the accessory navicular:

a) Type 1 accessory navicular has a cartilaginous interface (synchondrosis) with the navicular bone.

b) Type 2 accessory navicular is most commonly symptomatic.

c) Radiographs are usually diagnostic for os naviculare syndrome.

d) Tears of the posterior tibial tendon may be seen in os naviculare syndrome.

Question 3. Regarding the os trigonum:

a) It is best seen on the anterior-posterior projection of the ankle radiograph.

b) It may mimic a lateral talar process fracture.

c) Bright T1-weighted signal is a sign of bone marrow oedema in posterior ankle impingement syndrome.

d) Flexor hallucis longus tenosynovitis may be a feature in posterior ankle impingement syndrome.

Question 4. Regarding accessory ossicles:

a) The os peroneum is located within the peroneus brevis tendon.

b) Lateral foot pain is a feature of os peroneum syndrome.

c) The os intermetatarseum is located between the third and fourth metatarsals.

d) Fracture at the base of the fifth metatarsal may mimic an os vesalianum.

Question 5. Regarding sesamoids of the foot:

a) Hallucal sesamoids have medial and lateral components.

b) Bipartite sesamoid is most commonly seen in the lateral hallucal sesamoid.

c) Sesamoiditis most commonly involves the interphalangeal sesamoid.

d) Increased T2-weighted signal in the sesamoid is a feature of sesamoiditis.

\section{Doctor's particulars:}

Name in full:

Specialty:

MCR no.:

Email:

\section{SUBMISSION INSTRUCTIONS}

Visit the SMJ website: http://www.smj.org.sg/current-issue and select the appropriate quiz. You will be redirected to the SMA login page.

For SMA member: (1) Log in with your username and password (if you do not know your password, please click on 'Forgot your password?'). (2) Select your answers for each quiz and click 'Submit'.

For non-SMA member: (1) Create an SMJ CME account, or log in with your SMJ CME username and password (for returning users). (2) Make payment of SGD 21.40 (inclusive of $7 \%$ GST) via PayPal to access this month's quizzes. (3) Select your answers for each quiz and click 'Submit'.

RESULTS:

(1) Answers will be published online in the SMJ June 2018 issue. (2) The MCR numbers of successful candidates will be posted online at the SMJ website by 7 June 2018 . (3) Passing mark is $60 \%$. No mark will be deducted for incorrect answers. (4) The SMJ editorial office will submit the list of successful candidates to the Singapore Medical Council. (5) One CME point is awarded for successful candidates. (6) SMC credits CME points according to the month of publication of the CME article (i.e. points awarded for a quiz published in the December 2017 issue will be credited for the month of December 2017, even if the deadline is in January 2018).

Deadline for submission: (April 2018 SMJ 3B CME programme): 12 noon, 31 May 2018. 